\title{
Prevalence of Candida albicans and non-albicans isolates from vaginal secretions: comparative evaluation of colonization, vaginal candidiasis and recurrent vaginal candidiasis in diabetic and non-diabetic women
}

Prevalência de Candida albicans e não albicans isoladas de secreção vaginal: avaliação comparativa entre colonização, candidíase vaginal e candidíase vaginal recorrente em mulheres diabéticas e não diabéticas

Luciene Setsuko Akimoto Gunther', Helen Priscila Rodrigues Martins", Fabrícia Gimenes'", André Luelsdorf Pimenta de Abreu'v , Marcia Edilaine Lopes Consolarov ${ }^{\vee}$, Terezinha Inez Estivalet Svidzinskiv Department of Clinical Analysis and Biomedicine, Universidade Estadual de Maringá (UEM), Maringá, Paraná, Brazil

'MSc. Professor, Department of Clinical Analysis and Biomedicine, Universidade Estadual de Maringá (UEM), Maringá, Paraná, Brazil.

"MSc. Nurse, Municipal Health Department of Curitiba, Curitiba, Paraná, Brazil.

I"PhD. Postdoctoral Student, Department of Clinical Analysis and Biomedicine, Universidade Estadual de Maringá (UEM), Maringá, Paraná, Brazil.

"MSc. Postgraduate Doctoral Student, Department of Clinical Analysis and Biomedicine, Universidade Estadual de Maringá (UEM), Maringá, Paraná, Brazil.

YPhD. Professor, Department of Clinical Analysis and Biomedicine, Universidade Estadual de Maringá (UEM), Maringá, Paraná, Brazil.

KEY WORDS:

Candida.

Candidiasis, vulvovaginal

Diabetes mellitus.

Fluconazole.

Therapeutics.

\section{PALAVRAS-CHAVE:}

Candida.

Candidíase vulvovaginal.

Diabetes mellitus.

Fluconazol.

Terapêutica.

\begin{abstract}
CONTEXT AND OBJECTIVE: Vulvovaginal candidiasis (VVC) is caused by abnormal growth of yeast-like fungi on the female genital tract mucosa. Patients with diabetes mellitus (DM) are more susceptible to fungal infections, including those caused by species of Candida. The present study investigated the frequency of total isolation of vaginal Candida spp., and its different clinical profiles - colonization, VVC and recurrent WVC (RVVC) - in women with DM type 2, compared with non-diabetic women. The cure rate using fluconazole treatment was also evaluated.

DESIGN AND SETTING: Cross-sectional study conducted in the public healthcare system of Maringá, Paraná, Brazil.

METHODS: The study involved 717 women aged 17-74 years, of whom 48 (6.7\%) had DM type 2 (mean age: 53.7 years), regardless of signs and symptoms of WVC. The yeasts were isolated and identified using classical phenotypic methods.

RESULTS: In the non-diabetic group (controls), total vaginal yeast isolation occurred in 79 (11.8\%) women, and in the diabetic group in $9(18.8 \%)(P=0.000)$. The diabetic group showed more symptomatic $(V V C+$ RVVC $=66.66 \%)$ than colonized (33.33\%) women, and showed significantly more colonization, VVC and RVVC than seen among the controls. The mean cure rate using fluconazole was $75.0 \%$ in the diabetic group and $86.7 \%$ in the control group $(P=0.51)$.

CONCLUSION: We found that DM type 2 in Brazilian women was associated with yeast colonization, VVC and RVVC, and similar isolation rates for C. albicans and non-albicans species. Good cure rates were obtained using fluconazole in both groups.
\end{abstract}

\section{RESUMO}

CONTEXTO E OBJETIVO: Candidíase vulvovaginal (CV) é causada pelo crescimento anormal de fungos do tipo leveduras na mucosa do trato genital feminino. Pacientes com diabetes mellitus (DM) são mais susceptíveis a infecções fúngicas, incluindo por espécies de Candida. O presente estudo investigou a frequência de isolamento total de Candida spp. vaginal, e diferentes quadros clínicos (CVV e CV recorrente(VVR) em mulheres com DM tipo 2 comparadas às não diabéticas. A razão de cura do tratamento com fluconazol também foi avaliada.

TIPO DE ESTUDO E LOCAL: Estudo transversal realizado no sistema público de saúde de Maringá, Paraná, Brazil. MÉTODO: O estudo envolveu 717 mulheres de 17-74 anos de idade e, destas, 48 (6,7\%) tinham DM 2 (média de 53,7 anos), independentemente de sinais e sintomas de CV. As leveduras foram isoladas e identificadas por métodos fenotípicos clássicos.

RESULTADOS: No grupo de não diabéticas (controle), leveduras vaginais totais foram isoladas em 79 $(11,8 \%)$ mulheres, e no grupo de diabéticas, em $9(18,8 \%)(P=0,000)$. O grupo de diabéticas mostrou mais mulheres sintomáticas ( $C V V+C V V R=66,66 \%)$ do que colonizadas (33.33\%), e significativamente mais coIonização, CVV e CVVR, que as controle. A razão média de cura com fluconazol foi de $75.0 \%$ no grupo diabéticas e $86.7 \%$ no controle $(P=0.51)$.

CONCLUSÃO: Nós encontramos que DM 2 em mulheres brasileiras associou-se com colonização vaginal por leveduras, CVV e CVVR, razão similar de isolamento de C. albicans e espécies não albicans. Boa taxa de cura foi obtida com fluconazol em ambos os grupos. 


\section{INTRODUCTION}

Vulvovaginal candidiasis (VVC) is classified by the World Health Organization (WHO) as a pathological condition that is frequently sexually transmitted (STD). ${ }^{1}$ Because it affects millions of women annually, thereby causing great discomfort, interfering with sexual and affective relations and impairing work performance, VVC has been considered to be an important worldwide public health problem. ${ }^{2}$

VVC is caused by abnormal growth of yeast-like fungi on the mucosa of the female genital tract. It is clinically characterized by occurrences of intense vulvar itching, leucorrhea, dyspareunia, dysuria, edema and vulvovaginal erythema. ${ }^{2,3}$ Vaginal yeasts become pathogenic when the colonization site on the host is favorable to their development. Several factors may increase this risk, such as previous colonization by the yeast, immunosuppressive diseases, diabetes mellitus (DM) and other factors. ${ }^{4,5}$

Patients with DM are more susceptible to bacterial and fungal infections, including those caused by species of Candida. ${ }^{6}$ Some investigators have suggested that VVC occurs more frequently in diabetic women, and others that a correlation exists between hyperglycemia and VVC., ${ }^{2,7}$ However, few studies have addressed the problem of VVC among Brazilian diabetic women.

\section{OBJECTIVE}

The objective of this study was to determine the frequency of total isolation of vaginal Candida spp., and the clinical profiles, VVC and recurrent VVC (RVVC), in women with DM type 2, compared with non-diabetic women. The cure rate from fluconazole treatment was also evaluated.

\section{METHODS}

This experimental study involved women aged between 17 and 74 years who participated in the Cervical Cancer Triage Program, regardless of signs and symptoms of VVC, between January 1 and December 31, 2010, in the public healthcare system of Maringá, Paraná, Brazil. Six healthcare centers participated in the study. This study was approved by the Ethics Committee for Research on Humans (COPEP) at Universidade Estadual de Maringá (UEM) (185/2007). The exclusion criteria were pregnancy or a history of immunosuppressive disease, including AIDS. The women answered a standardized questionnaire that sought information regarding VVC symptoms. Subjects were identified as affected by DM type 2 according to the American Diabetes Association (ADA) definition, if their fasting serum glucose was $7 \mathrm{mmol} / \mathrm{l}$ $(126 \mathrm{mg} / \mathrm{dl})$ or more, as reported in the patients' medical records.

A vaginal sample was collected using a sterile swab, inoculated in sterile saline and sent to the Medical Mycology Laboratory at UEM, where it was immediately seeded onto plates containing Sabouraud dextrose agar (SDA) (Difco, United States) with $100 \mathrm{mg} / \mathrm{ml}$ of chloramphenicol, and incubated at $25^{\circ} \mathrm{C}$ for five days. A pool of the colonies grown on each plate was subcultured in CHROMagar Candida medium (Probac, France). Beginning with the pure culture, the yeasts were identified using classical phenotypic methods. ${ }^{8}$

The clinical profiles of the women with positive culture for yeasts were classified into three types: colonized, but without symptoms of VVC; with VVC, presenting an acute episode with at least two of the following symptoms: discharge, itching, dysuria and dyspareunia; and with recurrent VVC (RVVC), presenting two or more of these symptoms and at least four episodes in twelve months. ${ }^{9}$ Women who had RVVC were counted only once.

All the women in the diabetic group and 28 in the non-diabetic group with cultures positive for yeasts were treated, independent of clinical profile, using oral fluconazole (Neoquímica, Brazil) at a single dose of $150 \mathrm{mg}$ weekly for two weeks. They were instructed to return 20 days after the end of treatment, so that material for a new yeast culture could be collected.

The data were analyzed by means of the chi-square test, using the STATA for Statistics and Data Analysis 9.1 software. All variables were expressed as absolute and relative frequencies. $\mathrm{P}$ values $<0.05$ were considered significant.

\section{RESULTS}

Figure 1 shows an overview of the study. A total of 717 women were included, of whom 48 (6.7\%) had DM type 2 (mean age: 53.7 years). In the control group (mean age: 43.3 years), total vaginal yeast isolation occurred in $79(11.8 \%)$ women, distributed as C. albicans ( $\mathrm{n}=43 ; 54.4 \%)$ and non-albicans species $(\mathrm{n}=36$; $45.6 \%$ ) (odds ratio $[\mathrm{OR}]=7 ; 2.2-11.5 ; \mathrm{P}=0.02$ ). In no case was more than one yeast species isolated.

In the diabetic group, total yeast isolation occurred in 9 women $(18.8 \%)$, which was a higher proportion than among the controls $(\mathrm{OR}=7.77 ; 3.88-15.56 ; \mathrm{P}=0.000)$, distributed as C. albicans $(\mathrm{n}=5 ; 55.6 \%)$ and non-albicans species $(\mathrm{n}=4 ; 44.4 \%)$ $(\mathrm{P}=0.2)$ (Table 1).

Among the non-albicans species, C. glabrata was the most frequent isolate in both the controls $(n=23 / 79 ; 29.1 \%)$ and the diabetic group ( $n=3 / 9 ; 33.3 \%$ ).

With regard to clinical profiles, in the control group 24/79 women $(30.4 \%)$ were colonized or had VVC or RVVC (55/79; 69.9\%) $(\mathrm{P}=0.411)$, with no significant difference between $\operatorname{VVC}(44 / 79 ; 55.7 \%)$ and $\operatorname{RVVC}(11 / 79,13.9 \%)(\mathrm{P}=0.201)$. In the diabetic group, more women were symptomatic (VVC + $\mathrm{RVVC}=3 / 9,66.66 \%)$ than colonized $(3 / 9 ; 33.33 \%)(\mathrm{OR}=0.5$; 0.125-1.999; P = 0.005) (Table 1).

The diabetic women showed a significantly higher proportion of colonization $(\mathrm{OR}=5 ; 2.08-23.46 ; \mathrm{P}=0.005)$, VVC + RVVC $(\mathrm{OR}=5 ; 2.50-10.44 ; \mathrm{P}=0.004), \mathrm{VVC}(\mathrm{OR}=13 ; 4.23-49.13$; 


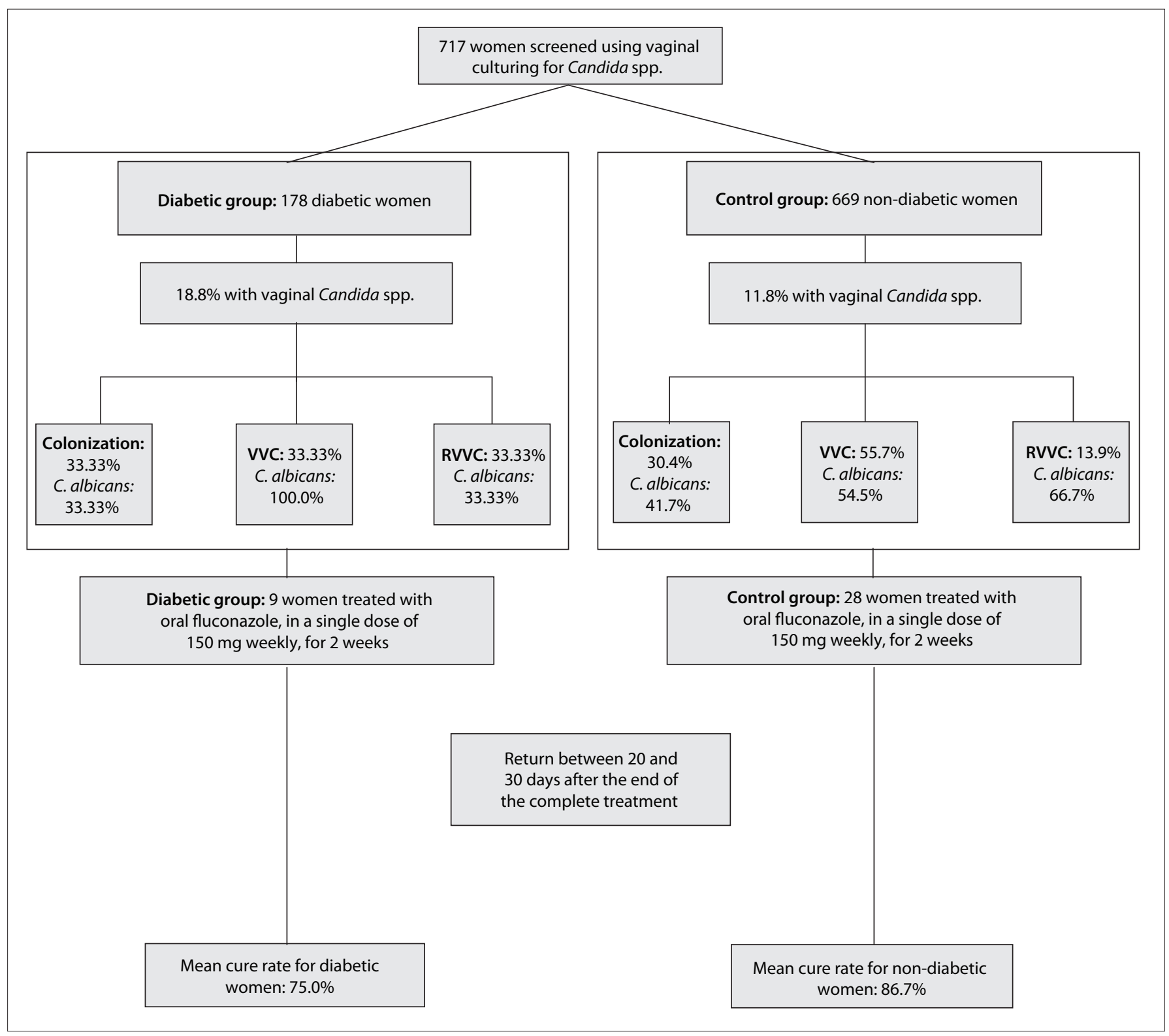

Figure 1. An overview of the study and its results.

Table 1. Frequency of total isolation of vaginal Candida spp. and the clinical conditions of colonization, vulvovaginal candidiasis (VVC) and recurrent VVC (RVVC) among diabetic and non-diabetic women in the public healthcare system of Maringá, Paraná, Brazil

\begin{tabular}{|c|c|c|c|c|c|c|c|c|c|c|c|c|c|c|c|c|}
\hline \multirow{3}{*}{$\begin{array}{l}\text { Candida } \\
\text { species }\end{array}$} & \multicolumn{7}{|c|}{$\begin{array}{l}\text { Diabetic group } \\
\qquad(n=48)\end{array}$} & \multicolumn{9}{|c|}{$\begin{array}{l}\text { Non-diabetic group } \\
\qquad(n=669)\end{array}$} \\
\hline & \multicolumn{2}{|c|}{ Total isolation } & \multicolumn{2}{|c|}{ Colonization* } & \multicolumn{2}{|c|}{ VVC $^{*}$} & \multicolumn{2}{|c|}{ RVVC $^{*}$} & \multicolumn{2}{|c|}{ Total isolation } & \multicolumn{2}{|c|}{ Colonization } & \multicolumn{2}{|c|}{ VVC } & \multicolumn{2}{|c|}{ RVVC } \\
\hline & $n$ & $\%$ & $n$ & $\%$ & $\mathrm{n}$ & $\%$ & $\mathrm{n}$ & $\%$ & $n$ & $\%$ & $n$ & $\%$ & $\mathrm{n}$ & $\%$ & $n$ & $\%$ \\
\hline Non-albicans & 4 & 44.4 & 2 & 66.7 & - & - & 2 & 66.7 & 36 & 45.6 & 14 & 58.3 & 20 & 45.5 & 2 & 33.3 \\
\hline Total & 9 & 18.8 & 3 & 33.3 & $3^{\ddagger}$ & 33.3 & $3^{\ddagger}$ & 33.3 & 79 & 11.8 & $24^{\S}$ & 30.4 & $44^{\S}$ & 55.7 & $11^{\S}$ & 13.9 \\
\hline
\end{tabular}

$\mathrm{n}=$ number; $\mathrm{VVC}=$ vulvovaginal candidiasis; RVVC = recurrent vulvovaginal candidiasis.

"Total Candida spp. isolation (clinical conditions: colonization, VVC and RVVC) was significantly greater in the diabetic group $(P=0.000) ;{ }^{\dagger} \mathrm{C}$. albicans was the most frequent species isolated in the non-diabetic group ( $\mathrm{P}=0.02)$ considering only total Candida spp. isolation, but not for different clinical conditions (colonization, VVC and RVVC) ( $P>0.05$ ); "Diabetic group showed more symptomatic women (VVC and RVVC) than colonized women (odds ratio, OR = 0.5; 0.125-1.999;

$P=0.005)$. ${ }^{5}$ Control group was equally colonized or had VVC or RVVC $(P=0.411)$, without significant difference between VVC and RVVC $(P=0.201)$.

Diabetic group showed more colonization $(\mathrm{OR}=5 ; 2.08-23.46 ; \mathrm{P}=0.005), \mathrm{VVC}+\mathrm{RVVC}(\mathrm{OR}=5 ; 2.50-10.44 ; \mathrm{P}=0.004), \mathrm{VVC}(\mathrm{OR}=13 ; 4.23-49.13 ; \mathrm{P}=0.000)$ and

RVVC $(O R=2.6 ; 0.70-10.05 ; P=0.000)$ than seen in the controls. 
$\mathrm{P}=0.000)$ and $\mathrm{RVVC}(\mathrm{OR}=2.6 ; 0.70-10.05 ; \mathrm{P}=0.000)$ than seen in the controls.

A total of 8 women in the diabetic group and 15 in the nondiabetic group correctly concluded the treatment with fluconazole, with mean cure rates of $75.0 \%$ and $86.7 \%$ respectively $(\mathrm{P}=0.51)$. In both the diabetic and the control group, C. glabrata and $C$. tropicalis showed resistance to fluconazole.

\section{DISCUSSION}

We found that DM type 2 in Brazilian women was associated with Candida spp. colonization, VVC and RVVC; and that the cure rate with fluconazole was satisfactory. Other investigators have described associations between DM and VVC, colonization and RVVC, in different countries. ${ }^{6,10}$ This is very worrisome because VVC afflicts millions of both non-diabetic and diabetic women, causing great discomfort and interfering with sexual and affective relations. ${ }^{2,3}$ Uncontrolled DM causes metabolic alterations, such as increased levels of glycogen, which can significantly increase colonization and infection by Candida. ${ }^{11}$ The increased glycogen level lowers the vaginal $\mathrm{pH}$, thereby facilitating development of VVC. ${ }^{12}$

The women with DM studied here showed similar rates of $C$. albicans and non-albicans species, thus differing from the control group. The rates were similar to those reported by Lattif et al. ${ }^{10}$ and Faraji et al. ${ }^{13}$ In some populations, there has been an increase in the isolation of vaginal non-albicans species, but most investigators agree that this does not seem to be a general trend. ${ }^{10,13}$

The relatively high cure rate with fluconazole in both diabetic and non-diabetic women shows that this is a good therapeutic option even for Brazilian women with diabetes, who require attention to treatment of non-albicans species, particularly $C$. glabrata, which are intrinsically less susceptible to azole antifungals. ${ }^{3,14}$ Similarly to our results, Brumar et al. ${ }^{7}$ also reported a high cure rate with fluconazole (85.71\%) in diabetic women with VVC.

We acknowledge that the number of diabetic women in our study was small, and that this group may not fully represent populations of diabetic women. Nevertheless, the number of diabetics $(\mathrm{n}=48)$ was relatively high in this population of 717 women, and we believe that this study contributes important information for management of diabetic women with vaginal Candida spp. However, the interaction between DM type 2 and vaginal Candida species merits further evaluation in relation to glycemic control, in a larger sample of diabetic women in Brazil.

\section{CONCLUSION}

We found that diabetes in Brazilian women was associated with yeast colonization, VVC and RVVC, with similar isolation rates for C. albicans and non-albicans species; and that the cure rate with fluconazole was relatively high. Although regarded as a trivial infection by some, the increasing incidence of VVC associated with diabetes raises additional issues regarding prevention and patient management.

\section{REFERENCES}

1. Reese RE, Betts RF. Antibiotic use. In: Reese RE, Betts RF, editors. A practical approach to infectious disease. $3^{\text {rd }}$ ed. Boston: Little, Brown and Company; 1991. p. 821-1007.

2. Sobel JD. Vulvovaginal candidosis. Lancet. 2007;369(9577):1961-71.

3. Wei Y, Feng J, Luo ZC. Isolation and genotyping of vaginal nonalbicans Candida spp. in women from two different ethnic groups in Lanzhou, China. Int J Gynaecol Obstet. 2010;1 10(3):227-30.

4. Souza PC, Storti-Filho A, Souza RJ, et al. Prevalence of Candida sp. in the cervical-vaginal cytology stained by Harris-Shorr. Arch Gynecol Obstet. 2009;279(5):625-9.

5. Hetticarachchi N, Ashbee HR, Wilson JD. Prevalence and management of non-albicans vaginal candidiasis. Sex Transm Infect. 2010;86(2):99-100.

6. Antony G, Saralaya V, Gopalkrishna-Bhat K, et al. Effect phenotypic switching on expression of virulence factors by Candida albicans causing candidiasis in diabetic patients. Rev Iberoam Micol. 2009;26(3):202-5

7. Brumar A, Rosu AF, Calina D, et al. Study concerning vulvovaginal candidiasis in women with diabetes. European Journal of Hospital Pharmacy Science and Practice. 2012;19(2):213. Available from: http://ejhp.bmj.com/content/19/2/213.1.short. Accessed in 2013 (Jun 11).

8. Kurtzman CP, Fell JW. The yeasts. A taxonomic study. $4^{\text {th }}$ ed. Amsterdam: Elsevier; 1998.

9. Chassot F, Camacho DP, Patussi EV, et al. Can Lactobacillus acidophilus influence the adhesion capacity of the Candida albicans on the combined contraceptive vaginal ring? Contraception. 2010;81(4):331-5.

10. Lattif AA, Mukhopadhyay G, Banerjee U, Goswami R, Prasad R. Molecular typing and in vitro fluconazole susceptibility of Candida species isolated from diabetic and nondiabetic women with vulvovaginal candidiasis in India. J Microbiol Immunol Infect. 2011;44(1):166-71

11. Corrêa PR, David PRS, Peres NP, et al. Caracterização fenotípica de leveduras isoladas da mucosa vaginal em mulheres adultas [Phenotypic characterization of yeasts isolated from the vaginal mucosa of adult women]. Rev Bras Ginecol Obstet. 2009;31 (4):177-81.

12. Carrara MA, Bazotte RB, Donatti $L$, et al. Effect of experimental diabetes on the development and maintenance of vulvovaginal candidiasis in female rats. Am J Obstet Gynecol. 2010;200(6):659.e1-4.

13. Faraji R, Rahimi MA, Rezvanmadani F, Hashemi M. Prevalence of vaginal candidiasis infection in diabetic women. African Journal of Microbiology Research. 2012;6(11):2773-8. Available from: http:// www.academicjournals.org/ajmr/pdf/Pdf2012/23\%20March/ Faraji\%20et\%20al.pdf. Accessed in 2013 (Jun 11). 
14. Dalben-Dota KF, Faria MG, Bruschi ML, et al. Antifungal activity of propolis extract against yeasts isolated from vaginal exudates. J Altern Complement Med. 2010;16(3):285-90.

Sources of funding: The present study was supported by a grant from Fundação Araucária de Apoio ao Desenvolvimento Tecnológico e Científico do Paraná, Brazil, protocol number 15.025/2009

\section{Conflict of interest: None}

Date of first submission: December 3, 2012

Last received: April 18, 2013

Accepted: June 19, 2013

Address for correspondence:

Marcia Edilaine Lopes Consolaro

Departamento de Análises Clínicas e Biomedicina

Universidade Estadual de Maringá

Av. Colombo, 5.790

Zona 07 - Maringá (PR) - Brasil

CEP 87020-900

Tel. (+55 44) 3011- 4795/3011-5996

E-mail:melconsolaro@gmail.com 